\title{
REFORMA AGRÁRIA NO BRASIL: ALGUMAS CONSIDERAÇÕES SOBRE A MATERIALIZAÇÃO DOS ASSENTAMENTOS RURAIS
}

\author{
REFORMA AGRARIA EM BRASIL: ALGUNAS CONSIDERACIONES \\ ACERCA DE LA MATERIALIZACIÓN DE LOS ASENTAMIENTOS \\ RURALES
}

\section{AGRARIAN REFORM IN BRAZIL: SOME CONSIDERATIONS ABOUT THE MATERIALIZATION OF RURAL SETTLEMENTS}

\author{
Prof. Dr. Marco Antonio Mitidiero Junior \\ Universidade Federal da Paraíba \\ mitidierousp@yahoo.com.br
}

\begin{abstract}
Resumo: Este artigo visa discutir em linhas gerais algumas questões e problemas que o processo de assentamento de famílias sem terra traz à tona, assumindo como parâmetro analítico certo referencial teórico e conceitual já consolidado na Geografia. Dessa forma, objetiva-se discutir a materialização da luta pela terra representada pelo Projeto de Assentamento e o tratamento científico que o tema vem recebendo. Para realizar a referida reflexão, parte-se do reconhecimento de que o Estado, sobretudo nos últimos vinte anos dos governos federais que se sucederam, não é o único e principal protagonista do surgimento dos Projetos de Assentamentos de Reforma Agrária. Pelo contrário, a sociedade civil organizada em movimentos sociais no campo é quem pressiona o Estado para a realização da Reforma Agrária. Durante as diferentes etapas que caracterizam o processo de assentamento, surge uma série de problemas decorrentes da transformação de família sem terra para família assentada, pequena produtora rural. No bojo desse processo a relação que estabelecem Estado, famílias assentadas e movimentos sociais apresenta-se de forma conflituosa, produzindo uma série de limitações à concretização da conquista da terra.
\end{abstract}

Palavras chaves: luta pela terra, assentamento, materialização, movimentos sociais, Estado.

Resumen: Este artículo objetiva discutir en líneas generales algunos dilemas que el proceso de asentamiento de familias sin tierra trae en discusión, asumiendo como parámetro analítico cierto referencial teórico y conceptual ya consolidado en la Geografía. De esta forma se propone a discutir la materialización de la lucha por la tierra representada por el Proyecto de Asentamiento y el tratamiento científico que el tema viene recibiendo. La referida reflexión parte del reconocimiento que el Estado, a los últimos veinte años de los gobiernos federales que se sucedieron, no es el único y principal protagonista del surgimiento de los Proyectos de Asentamiento de Reforma Agraria. Al contrario, la sociedad civil organizada en movimientos sociales en el campo es quien achucha el Estado para la realización de la Reforma Agraria. A lo largo de las distintas etapas que caracterizan el proceso de asentamiento, surge una serie de problemas decurrentes de transformación de familia sin tierra para familia asentadas (o con espacio de tierra para el cultivo), pequeña productora rural. En la clave de este proceso la relación Estado, familias asentadas y movimientos sociales se presenta una construcción en conflictos, produciendo una serie de limitaciones a la concretización de la lucha de la tierra. 
Palabras claves: lucha, lucha por la tierra, asentamiento, materialización, movimientos sociales, Estado.

Abstract: This paper discusses in general terms some dilemmas that the process ofsettlement of landless families brings up, assuming certain analytical parametertheoretical and conceptual already consolidated in geography. Thus, the objective is to discuss the realization of the land struggle represented by the Settlement Project and scientific treatment of the topic has received. To accomplish the above discussion, it starts from the recognition that the state, especially in the last twenty years the federal government that followed, is not the only and mainprotagonist of the emergence of the Project for Agrarian Reform Settlements.Rather, civil society organizations in social movements in the field who is pressingthe state for the implementation of land reform. During the different stages thatcharacterizes the process of settlement, there is a series of problems arising from the transformation of landless families for family sitting, small rural producer. In the midst of this process the relationship between the State, settled families and social movements is presented in a confrontational, producing a number oflimitations to achieving the conquest of the land.

Key words: struggle for land settlement, materialization, social movements, state.

\section{APRESENTAÇÃO}

Conhecer e pesquisar projetos de assentamentos rurais de reforma agrária em diferentes estados ou regiões do Brasil é certamente um evento recente na história nacional. É também um fato que vem trazendo entusiasmo à maioria dos pesquisadores interessados nos temas que envolvem a questão agrária e para aqueles que defendem a realização de uma reforma agrária ampla e massiva.

Foi nos últimos 20 anos que ocorreu o maior número de assentamentos rurais, talvez esse seja um dos eventos mais marcantes da nossa formação territorial contemporânea, ao lado da ampliação acelerada das monoculturas de exportação comandada pelo agronegócio.

Um ponto de partida básico para se entender esse processo é reconhecer que o Estado, através dos seus sucessivos governos, não é o único e principal protagonista do surgimento dos Projetos de Assentamentos (PAs). Pelo contrário, a sociedade civil organizada em movimentos sociais no campo é quem pressiona o Estado para a realização de PAs. Como costumam proferir muitos defensores dos movimentos sociais: no Brasil não há reforma agrária, mas sim luta organizada pela terra, ou seja, são as ações de reivindicação e luta pela terra, organizadas pelos já populares 'sem terra', que produzem ações institucionais de desapropriação de fazendas e áreas rurais que não cumprem função social exigida pela Constituição Federal de 1988. Não é por menos que a expressão "conquista da terra" é bradada por muitos militantes desses 
movimentos sociais, uma vez que a noção de conquista carrega em si a luta contra o latifúndio e a pressão frente ao Estado. Tal compreensão leva a conclusão de que, sem a existência dos movimentos sociais reivindicatórios, não haveria assentamentos rurais espacializados por todo o território nacional.

Este artigo visa discutir, em linhas gerais, algumas questões e problemas que o processo de assentamento de famílias sem terra traz à tona. A transformação de sem terra em assentado e de assentado em pequeno produtor rural é repleta de percalços e desafios, por isso de luta contínua, agora na terra. Pode-se reconhecer, no decorrer desse processo, dois momentos umbilicalmente interligados, que são: a luta pela terra seguida pela luta na terra. Assim, o interesse dessa reflexão é discutir a materialização do projeto de assentamento, e não a realização da reforma agrária. Essa discussão terá como pano de fundo uma reflexão sobre alguns conceitos já consolidados na Geografia para a interpretação do tema proposto, bem como tentará vislumbrar outro ponto de partida teórico e conceitual para tratamento do referido tema. Em outras palavras, o interesse científico está em refletir a respeito das questões presentes na transformação de sem terra em assentado. Para isso, este pesquisador valer-se-á de informações coletadas nos estados de São Paulo, Minas Gerais, Bahia e Paraíba, entretanto dará ênfase às informações provindas do estado de Sergipe, em específico do Alto Sertão sergipano ${ }^{1}$.

\section{UTOPIAS EM PROCESSO}

Para essa reflexão é interessante dar significado à palavra/conceito de utopia como negação da ordem estabelecida. Dessa forma, a riqueza das ações e práticas imbuídas de utopia por movimentos sociais rurais estaria mais na negação de situações sociais e territoriais injustas do que na construção de uma nova sociedade e de um novo território. Se bem que, no momento de luta pela terra, nas situações de ocupação e acampamento, as utopias que envolvem projetos de transformação social radical possuem um dispositivo de fortalecimento e esperança para aqueles que estão em luta, servindo como "fermento" das ações - como profetiza a Comissão Pastoral da Terra (CPT) - para a transformação das suas condições de vida, tudo isso sob o signo de

\footnotetext{
${ }^{1} \mathrm{O}$ presente artigo não visa explicitar e localizar dados coletados e sistematizados em aproximadamente 13 anos de pesquisas. Esses dados serão o ponto de partida para a reflexão proposta. Como a definição de conceitos científicos requer um grau de abstração, essa discussão refletirá a abstração desses dados coletados em muitos anos de pesquisa. Contudo, alguns dados empíricos obtidos no Alto Sertão Sergipano serão, resumidamente, relatados ao leitor.
} 
construção de uma nova sociedade e um novo território. Entretanto, um porto seguro para iniciar a reflexão é entender utopia como negação da ordem, esta representada pela concentração fundiária em conflito com um sem número de famílias sem terra. Essa utopia, no acontecer da luta, acaba por anteceder o futuro, que, no caso dos sem terra, é o futuro na terra com sua família.

É na materialização da conquista da terra que emerge uma série de dilemas e questionamentos que, a meu ver, devem ser encarados de frente pelos pesquisadores, movimentos sociais e pelo Estado, uma vez que problemas socioeconômicos e políticos marcam o processo de efetivação dos assentamentos em todo o Brasil. Sendo que o trabalho na terra e a produção de alimentos, a princípio objetivos elementares da luta pela terra e da realização da reforma agrária, aparecem como grandes gargalos na transmutação de sem terra a assentado.

O Estado é quem dita os passos e as técnicas para o assentamento das famílias. É nesse processo que os problemas tomam corpo, como por exemplo: morosidade no processo de desapropriação; lentidão das demandas que se dão no âmbito judicial; demora na demarcação dos lotes e construção das casas; lentidão na materialização de outras infraestruturas necessárias; descompasso no sistema de créditos e fragilidade quando existem - dos programas de assistência técnica e assistência à comercialização, o que dificulta efetivamente a construção do assentamento em uma área de produção agropecuária.

No âmbito político, parte-se da constatação de que a maioria dos assentamentos é resultado de luta e pressão sobre o Estado, porém, a conquista da terra e a realização do assentamento, muitas vezes, fazem esmaecer a situação de movimento, enfraquecendo a capacidade de organização dos assentados em comparação à condição de acampamento. Uma máxima que se pode encontrar com facilidade na coleta de informações em assentamentos rurais é que "no acampamento o povo era mais unido", por isso as ações/reivindicações eram mais efetivas e contundentes.

Essa realidade coloca, de um lado, o Estado ora deficiente na realização das políticas públicas, ora cooptado nos assuntos da questão agrária e, de outro lado, a organização social enfraquecida e sumariamente perseguida pelo próprio Estado, pela velha oligarquia rural e pela mídia. Além disso, o mercado é implacável nas relações econômicas que esse novo produtor rural assentado pode passar a desenvolver. Esse rol de impasses e limites faz com que as utopias criadas na luta pela terra distanciem-se da 
sua realização concreta. Contudo, vale levar em consideração a compreensão de Pierre Furter sobre as ações utópicas:

De nada serve julgar uma utopia em função do seu grau de realismo, mas deve-se apreciá-la em função do grau de negação da realidade que contém e da sua capacidade em despertar o entusiasmo para uma mutação da situação atual.

A utopia não somente indica aos outros a existência dos possíveis além do real, mas é também um instrumento de trabalho que permite a exploração sistemática de todas as possibilidades concretas existentes no real. Assim, a atitude utópica se apresenta não apenas como uma disposição para interpretar oniricamente a realidade, mas como uma necessidade de ação. (apud MORAIS, 1982:149)

Essa é uma interpretação válida ao entendimento das lutas sociais no campo, uma vez que as conquistas de terra fortemente impulsionadas por discursos utópicos significam a extinção de muitos latifúndios, realidade impensável há 30 anos. Entretanto, as dificuldades e limites da materialização do assentamento barram processos simbólicos e projeções tributárias das utopias criadas no bojo da luta. Como já foi indicado, a inércia do Estado e o enfraquecimento da situação de movimento podem trazer explicações, apontamentos e hipóteses. Também, uma ideia levantada por David Harvey para pensar as utopias e alternativas diante de uma sociedade capitalista pode ampliar a compreensão desse processo específico. Segundo esse autor:

\footnotetext{
As utopias da forma espacial pretendem tipicamente estabilizar e controlar os processos que têm que ser mobilizados para virem a se concretizar. Logo, no próprio ato de realização dessas utopias, o processo social toma as rédeas da forma espacial com que se pretende controlá-lo. (HARVEY, 2004: 228)
}

Para pensar a realização da reforma agrária, é válido transpor essa interpretação compreendendo que a idealização dos processos espaciais para os assentamentos rurais pode ocorrer à revelia das utopias sociais.

Duas experiências de assentamentos rurais mostram claramente a supremacia da utopia espacial frente às utopias sociais: 1) a imposição pelo Estado da estrutura espacial do assentamento, tendo como lugar de moradia a agrovila e; 2) o incentivo dos movimentos sociais pela organização da produção de forma coletiva. Ambas as iniciativas acabam por negar as utopias sociais da família camponesa. A construção da agrovila muitas vezes vai de encontro às idealizações dos camponeses de estarem na sua terra com a sua família, além disso, as agrovilas geralmente estão distantes dos lotes, portanto do lócus onde se projeta trabalho, dificultado as estratégias produtivas. A produção coletiva, pela qual tudo que se produz é de todos e todos trabalham em 
conjunto, também fere o ethos camponês ao negar o caráter individual/familiar que esses sujeitos sociais projetam no trinômio: terra, trabalho e família.

Em conclusão, quando a estrutura espacial é pensada sem a participação e a autonomia de decisão dos sujeitos sociais envolvidos, o processo de desenvolvimento desse novo espaço representado pelo assentamento tende a criar limitações à sua própria materialização. Os sujeitos sociais acabam por não assumir a utopia espacial exógena (governamental), desenvolvendo suas vidas em choque com as estruturas impostas. Nesse choque, como na assertiva de Harvey, o processo social toma as rédeas da forma espacial com que se pretende controlá-lo, porém em confronto com as políticas e projetos impostos, com a inércia do Estado e com o mercado.

Outro esboço teórico importante para pensar a materialização dos assentamentos rurais é a ideia de territorialização da luta pela terra levada a cabo pela espacialização dos movimentos sociais. A ocupação de terras, nesse contexto, caracteriza-se como forma de acesso à terra e como forma de recriação do campesinato. É por meio da espacialização das ações dos movimentos sociais de luta pela terra que a possibilidade da conquista do lugar de morada e do lugar da produção (assentamento rural) torna-se efetiva e materializa-se. É este processo que o conceito de territorialização busca explicar. Segundo Fernandes (1996:142):

O assentamento é uma fração do território conquistado. É um novo recurso na luta pela terra. Esse recurso significa parte das possíveis conquistas de territorialização. [...] Ao se territorializar, ao conquistar frações do território, territorializa-se na luta pela terra.

Essa noção, amiúde, significa que a conquista da terra territorializa a luta pela terra, gerando um novo território distinto da situação anterior (latifúndio). É importante notificar que essa proposição trouxe ao universo conceitual da Geografia a possibilidade de se pensar os movimentos sociais, já que suas ações são, também, fortemente territoriais. Jean-Yves Martim (2002) vai fundo nessa ótica e intitula o assentamento como uma novidade espacial.

Essa compreensão não existe sem críticas. Paulo Roberto Alentejano (2007) afirma que:

As interpretações teóricas acerca dos movimentos sociais na geografia são recentes. A principal tendência centra-se na busca de uma espacialidade/territorialidade dos movimentos sociais. O principal problema dessa linha de interpretação está na construção da ilusão da 
autonomia do controle sobre o território por parte dos movimentos sociais (p. 103).

O que não se considera aqui é que a conquista da terra de trabalho não representa mais que a ilusão da autonomia, pois a partir daí passam a operar outros mecanismos de subordinação. Afinal, as relações de trabalho e o regime de posse da terra são apenas parte das relações sociais de produção e não sua totalidade (p. 106).

O mesmo autor conclui que, numa sociedade capitalista, os mecanismos de dominação e subordinação são refeitos constantemente, sendo que os assentamentos não representam mais do que elementos de resistência das classes dominadas.

Na minha posição, vejo com restrições a adoção do conceito de territorialização da luta pela terra caso não leve em consideração os limites da materialização dessa luta em assentamentos rurais. Não se pode esquecer que o ato de desapropriação do latifúndio e o assentamento das famílias é uma atribuição do Instituto Nacional de Colonização e Reforma Agrária (Incra) ordenado pelo Presidente da República, em função disso, tanto as famílias assentadas como o movimento social dependem, até certa medida, das ações público-estatais (MITIDIERO, 2002:6) ${ }^{2}$.

Além de todo o processo burocrático e de decisão a cargo do Estado, um assentamento ainda fica refém de outras normas definidas pelas instituições públicas, como por exemplo, a exigência de associações; a elaboração de projetos e planos de desenvolvimento dos assentamentos; a tendência de construção das moradias em agrovilas; a influência diante de estratégias de geração de renda; os programas de crédito e etc ${ }^{3}$. É claro que essas ações, na maioria das vezes, nascem da pressão social erguida/gerada pelo próprio movimento social que lhe é tributário. Isso faz com que os assentados sejam um público diferenciado na relação Estado x agropecuária, eles são, ao mesmo tempo, produtos/produtores da luta organizada em movimentos sociais e

\footnotetext{
${ }^{2}$ Como lembra Leite (2004:65), "ao criar o assentamento, o Estado assume a responsabilidade de viabilizá-lo. Queira o Estado (na pessoa daqueles que o fazem existir) ou não, o desempenho de um assentamento é o desempenho de um Estado".

3 "Dito de outro modo, a outra face do privilégio que têm os assentados de ter condições de produção garantidas pelo Estado é estar completamente à mercê das ações ou omissões do Estado, o que não ocorre com o comum dos camponeses. Em compensação, o modo como se vinculam ao Estado, tem reconhecida uma legitimidade às suas cobranças, o que é negado aos que não fazem parte do mundo dos assentamentos. Cria-se, assim, um sistema de coerções e cobranças (potencial) recíprocas que resulta numa espécie de tensão permanente, cotidiana, mais próxima daquela que permeia relações como a que muitos assentados mantinham com patrões no passado do que a que costuma marcar o confronto de camponeses independentes com os poderes públicos" (LEITE, 2004:64).
} 
produto/produtores de ações institucionais ${ }^{4}$. Como aponta a pesquisa de Leite (2004), o assentamento pode ser visto como uma unidade territorial e administrativa que serve como referência às políticas públicas, distanciando-se da ideia de território autônomo.

Também, deve-se levar em consideração que o ex-sem terra é um sujeito social lançado livremente no mercado capitalista, e é com este mercado que o camponês, recém assentado, trava embates a fim de garantir sua reprodução social, sendo nestes embates que os mecanismos de subordinação tomam vida. Portanto, a territorialização vista como formação de um novo território, a partir de um território preexistente comandado pelo Estado e pelo mercado, e ainda, a concepção de que parte ou fração deste território se desprende formando um novo e pequeno território (o assentamento, a conquista da terra), torna-se insuficiente na sua dimensão explicativa.

O conceito de territorialização relativo aos movimentos sociais no campo deve ser visto apenas como processo de luta pela terra e não como conquista e domínio de partes ou frações do território. Em função desses eventos, a fração do território conquistada e transformada em assentamento rural pode ser vista como uma área de resistência subordinada diretamente constituinte do território capitalista brasileiro.

Para fortalecer as posições que concebem o assentamento como uma área de resistência subordinada, deve-se refletir sobre o processo social de assentamento, discutir informações que dão vida aos dilemas e às utopias dos assentados, mapeando a sociabilidade reinante nessa fração do território, suas relações com o entorno territorial (outros assentamentos, outras áreas agrícolas e municípios) e suas dificuldades de materialização enquanto ambiente de trabalho e organização social autônomos, onde foram projetadas utopias sociais.

Antes disso, farei uma série de apontamentos sobre os impactos territoriais que os assentamentos rurais, por si só, proporcionam no campo brasileiro. Assim será possível fazer uma contextualização mais abrangente na discussão sobre o processo de materialização dos assentamentos rurais.

\section{IMPACTOS TERRITORIAIS}

Mesmo que as informações sobre a situação socioeconômica dos assentamentos rurais não sejam empolgantes, mesmo que insucessos produtivos marquem muitos

\footnotetext{
${ }^{4}$ Medeiros e Leite (2004, p.19) concluem que "os estudos realizados sobre os assentamentos mostram que essas unidades têm sido criadas a partir de uma lógica de intervenção governamental que tem privilegiado a ação pontual sobre situações de conflitos".
} 
desses assentamentos, é inegável que a sua materialização em diferentes unidades da federação trouxe impactos territoriais de escala local e até regional. Parto da noção de que a organização da luta pela terra gera, frequentemente, pequenas remodelações no território nacional através do assentamento das famílias. $\mathrm{O}$ assentamento emerge diante de um território antes caracterizado pelo latifúndio improdutivo, pela terra abandonada, inativa, inercial e vazia. O projeto de assentamento governamental, levado a cabo pela contestação pública gerada pelos sujeitos sociais organizados, traz novas características ao território. O lugar, a região e as redes de relações que surgem a partir do povoamento pelos assentados do antigo latifúndio improdutivo dinamizam partes/frações do território brasileiro.

Entretanto, os impactos causados pelos assentamentos não se restringem a uma dimensão fisicalista e materialista do território, apontando para a interpretação do que chamei de materialização e impactos territoriais para além dessas dimensões. $O$ assentamento que se materializa em uma dada fração do território - concebido como um processo de territorialização - é produzido por sujeitos sociais carregados de utopias tanto espaciais como sociais.

Além disso, a realização do assentamento é um evento altamente político que se concretiza. Por isso, pensar na ideia de materialização é pensar na repercussão que o assentamento proporciona. Sua efetivação repercute tanto do ponto de vista material como do ponto de vista social e simbólico. O assentamento é um espaço remodelado, povoado ou repovoado, recortado e dividido. São construídas casas e estradas, realizamse lavouras e criações, realizam-se também encontros e reuniões que resultam em formação política, ocorrem manifestações, reivindicações, conflitos internos e externos, com isso toda uma dimensão política e cultural brota do projeto de assentamento. Concomitantemente, todo esse processo significa uma série de impactos sobre a família produtora dessa nova situação. Ela mesma é impactada, parte em razão das suas próprias ações. Como afirma Carvalho (1999:16), o assentamento é uma encruzilhada social:

[...] um agregado heterogêneo de grupos sociais, constituídos por famílias de trabalhadores que antes não possuíam terra e, dessa forma,se apossam formalmente das mesmas. Assim a partir desse momento, passam a se encontrar face a face nesse espaço físico, social, político, ambiental e econômico em que irão reproduzir seus meios de vida e trabalho. 
É importante a ressalva de Medeiros e Leite (2004:23) ao termo “impacto”. Segundo esses autores, o referido termo pode ser excessivo, uma vez que ele tende a chamar a atenção para o mais visível e espetacular, mas, muitas vezes, tem caráter molecular e só se potencializa ao longo do tempo. Na minha concepção, impacto, igualmente à definição de territorialização, constitui conceito explicativo de um processo social em curso, todavia o assentamento não deixa de ser um impacto imediato na desapropriação de um latifúndio. E como toda noção de impacto requer sua intensidade $^{5}$, dimensão e grau, no caso dos assentamentos essa intensidade pode variar segundo as especificidades históricas da região e da luta pela terra, da quantidade de assentados, da amplitude da produção e da geração de trabalho/empregos; atentando, também, para dimensões avessas a mensuração, como por exemplo, a constatação de que o cotidiano de luta pela terra acaba por formar politicamente parte dos sujeitos sociais envolvidos.

Caso a intensidade dos impactos seja medida estritamente pelos dados mercantis, como geralmente fazem os economistas, vale a ressalva de que toda atividade capitalista em um país capitalista está sujeita a oscilações do mercado e que o camponês produz alimentos para o autoconsumo da família, tendendo, portanto, para a imprecisão de qualquer tentativa de cristalizar os impactos a partir informações quantitativas de renda e comercialização. A forma de ser do campesinato compete a nada precisa expressão "produção de subsistência", uma vez que a produção camponesa relaciona historicamente o autoconsumo e a venda no mercado. No processo de assentamento, a possibilidade de realizar a produção impacta o cotidiano de uma família que antes não tinha possibilidade de produzir alimentos.

Não é difícil encontrar na literatura especializada outras interpretações sobre a materialização dos assentamentos rurais. Bergamasco (1997, p. 43) define os resultados da luta pela terra (assentamento) como um processo de socialização que vai repercutir em novos espaços sociais, econômicos, culturais e políticos, redefinindo as relações sociais em torno da posse da terra como ponto de partida para a redefinição de um conjunto de outras práticas sociais. Alentejano (1998) discute a realização da reforma agrária no contexto de luta organizada pela terra para a construção de um novo ordenamento no território brasileiro. Vera Lucia B. Ferrante $(1997)^{6}$ afirma que os

\footnotetext{
${ }^{5}$ Conforme Benetitti (2004, p. 53) "os efeitos dos assentamentos são de natureza, temporalidade e intensidade variáveis, segundo o contexto socioeconômico no qual estão inseridos" (ver Leite, 2004).

${ }^{6}$ Apud Miranda (1998, p. 19).
} 
assentamentos rurais são uma realidade em construção que, por seu dinamismo, não admitem seu enquadramento enquanto categorias sociológicas fechadas. Miranda (1998, p. 19) constata que:

A neolocalidade que caracteriza os assentados confere uma certa plasticidade a estes sujeitos, que se, por um lado, não podem ser vistos somente do ponto de vista econômico...

A mesma autora define que no assentamento está sendo gestado um neocampesinato, devido a novos valores e a novos saberes adquiridos, fundindo-se aos valores e saberes antigos.

Marques (2000:165) afirma que o caso estudado por ela é um território camponês em formação, assim:

Neste caso, o processo de Reforma Agrária pode ser entendido como um movimento particular no movimento mais amplo de reprodução camponesa no Brasil ...

Para Simonetti (1999), a análise dos assentamentos - como lugar conquistado/apropriado graças à luta pela terra, o que possibilita que esteja sob o controle/poder, mesmo parcial, dos camponeses - é o lugar conquistado, onde buscam desenvolver suas vidas de acordo com os seus sonhos e desejos. O novo estaria na territorialização do campesinato, e na consequente (re)produção do território camponês como resultado da luta pela terra. Segundo a autora:

Inicialmente, podemos considerar que a apropriação dessa fração do território capitalista pelos camponeses, permite romper, mesmo que parcialmente, com o poder das classes dominantes, e assim re-definir as relações de poder nesse lugar. (p. 8)

[...] embora se tenha clareza da subordinação dos camponeses à lógica capitalista, não é só isso que explica a persistência deles em seguir sendo camponeses. Persistem nessa luta para reafirmarem o seu modo de vida, ligado ao seu universo simbólico/cultural. (p. 56)

Moreira (2006:8) pensa o conceito de "território de esperança" como balizador da compreensão dos assentamentos rurais de reforma agrária, ressaltando o sentido de ruptura com as situações sociais pretéritas, sem deixar de atentar para as contradições do processo em voga. Para a autora o assentamento é um território de esperança: 
[...] aquele conquistado e construído: pela luta de resistência camponesa para permanecer na terra; pela luta de ocupação de terra, promovida pelos trabalhadores sem terra; pela luta de consolidação das diferentes formas de agricultura camponesa. Essas diferentes estratégias simbolizam formas de "ruptura" com o sistema hegemônico, isto é, com a organização social, econômica e política pré-existente no agro brasileiro. Na verdade, trata-se de um novo território, construído com base na utopia e na esperança. "Território de Esperança" [...] carregado de contradições, mas também de sinalizações de uma forma experienciada de organização social diferente daquela marcada pela exploração, dominação, pela bestialidade da exploração. Desse modo, "Território de Esperança" representa a superação do "Território de Exploração"[...]

Na concepção economicista de Abramovay (1998) ${ }^{7}$, os assentamentos como fator de desenvolvimento rural passam pela construção de novos territórios econômicos, isto é, "pela capacidade que terão os atores econômicos locais de manejar e valorizar ativos específicos às regiões em que habitam". Para Carvalho (1999), o assentamento representa a constituição de uma nova organização econômica, política, social e ambiental em determinada área, pela posse da terra por uma heterogeneidade social de famílias de trabalhadores rurais sem-terra. Fernandes $(1996 ; 1999 ; 2000)$ propõe que a atualidade da questão agrária brasileira está na territorialização, a um só tempo, dos camponeses, do movimento social e da luta pela terra. Sendo que a territorialização destes eventos sociais resultariam num escalonamento do território nacional, formando novos territórios.

A pesquisa coordenada por Sergio Leite (2004) - entre outros autores - trata igualmente da ideia de impacto para pensar os assentamentos rurais. Impactos são definidos, de forma ampla, como um processo que se refere à vida das famílias e sobre o local e em torno do assentamento. Assim, distanciam-se de um tema recorrente para julgar o sucesso ou o fracasso do assentamento que é a renda. Procuraram, mais do que quantificar a renda, qualificar as condições de vida dos assentados e sua possibilidade de acesso a serviços e bens. O assentamento, nessa ótica, é concebido como um novo espaço de sociabilidade comunitária e novas situações de inserção econômica, política e social.

Ainda, a mesma pesquisa realiza uma importante revisão bibliográfica sobre o tema, mostrando diversos estudos que aprofundam a compreensão sobre os processos em análise. O estudo de Lopes (2000 apud LEITE, 2004, p. 23$)^{8}$ produz dados negando

\footnotetext{
${ }^{7}$ Abramovay, Ricardo - Agricultura Familiar e Desenvolvimento Territorial. São Paulo, mimeo, 1998.

${ }^{8}$ Apud Leite, 2004, p. 23.
} 
a concepção de que os assentamentos são, apenas, lócus de produção unicamente para consumo doméstico, negando a popular expressão produção de subsistência. Lopes enfatiza as relações mercantis dos assentados mostrando que elas produzem, mesmo que precariamente, renda para permanecer no campo. Neves $(1996)^{9}$ constata que, na percepção dos assentados, há uma significativa melhoria nas condições de alimentação se comparadas com a situação anterior. Benedetti $(2000)^{10}$ mostra que uma fazenda desapropriada que empregava seis postos de trabalhos passou a receber 91 famílias, o que evidentemente elevou a geração de emprego na região. Leite e Medeiros (2002) ${ }^{11}$ levantaram informações, entre outras, sobre a organização social e produtiva, as condições de vida, as relações com o poder local e com as políticas públicas, a participação política, as alterações demográficas e na estrutura fundiária local e os efeitos ambientais decorrentes da materialização dos assentamentos rurais. Ieno Neto e Bamat (1998) ${ }^{12}$ chegam à conclusão de que a paisagem rural local foi transformada pela presença dos assentamentos, que intensificaram o uso e ocupação do solo, aumentando a diversificação de alimentos no mercado local.

Em localidades com a presença de vários assentamentos ou em assentamentos com grande quantidade de famílias pode ocorrer uma intensificação dos impactos territoriais. Ferreira e Fernandes $(2001)^{13}$ destacam a criação de aglomerados urbanos a partir dos PAs. Os equipamentos que geralmente são construídos em uma área de assentamento (escola, Igreja, áreas de lazer) são acrescidos por outros serviços, como: comércio, oficina mecânica, bares, lojas, armazéns, associações, serrarias, postos de gasolina, depósitos e etc.

Estudos como o de Ferrante (2000) ${ }^{14}$ mostram certas alterações no domínio do poder local. A pesquisa de Paula $(2001)^{15}$ constata a ocupação de postos no poder público municipal por assentados, representando um fato social absolutamente inovador. A meu ver, o assentamento que é produto de uma luta política aglutina sujeitos sociais contestadores e, especialmente, uma significativa quantidade de eleitores, que por si só podem alterar dinâmicas políticas locais, sobretudo em relação a pequenos municípios.

\footnotetext{
${ }^{9}$ Apud Leite, 2004, p. 24.

${ }^{10}$ Ibden nota 4.

${ }^{11}$ Ibden nota 4.

12 Apud Leite, 2004, p. 25.

${ }^{13}$ Ibden nota 7.

${ }_{14}^{14}$ Apud Leite, 2004, p. 26.

${ }^{15}$ Apud Leite, 2004, p. 27.
} 
É evidente que todos esses eventos, manifestações, acontecimentos que compõem o processo de assentamento negam uma situação social e territorial anterior, sinalizando para a constituição de novas formas de reprodução social (pelo menos para o sujeito envolvido) e novas configurações territoriais (do latifúndio ao recorte dos lotes do assentamento), impactando realidades locais e/ou regionais.

\section{A CONSTITUIÇÃO DE UMA RESISTÊNCIA SUBORDINADA OU PARA CONCLUIR}

A contradição que a expressão resistência subordinada visa elucidar parte das tensões e problemas que a materialização dos resultados da luta organizada pela terra traz à tona. As reflexões tratadas nesse artigo resultam de pesquisas realizadas sobre o tema em cinco estados brasileiros, sobretudo em Sergipe ${ }^{16}$. As pesquisas realizadas no alto sertão sergipano permitiram reunir uma série de premissas que direcionam a ideia de resistência e de subordinação. Para isso, a coleta e descrição de dados históricos dos processos de assentamento analisados levaram às seguintes considerações:

1 - Os movimentos sociais no campo não constituem movimentos políticos decisórios no âmbito das políticas de Estado que transformariam a estrutura fundiária e a produção/comercialização de alimento no Brasil, contudo conquistam frações de terra que lhes garantem um certo domínio territorial nas regiões ou municípios onde ocorrem.

É importante aprofundar a ideia de domínio territorial, uma vez que as forças políticas opostas tratam o assentamento rural como uma área de pequenas propriedades privadas, o que de fato não é. As terras da maior parte dos assentamentos rurais de reforma agrária são terras públicas, sobre as quais é concedido direito real de uso à família assentada, dentro de um programa de aquisição de terra adquirido/conquistado por essa família. Ou seja, o assentado rural é antes de tudo uma família que contraiu

\footnotetext{
${ }^{16}$ Em São Paulo e Minas Gerais foram os estados onde realizei pesquisas de campo para a dissertação de mestrado "O Movimento de Libertação dos Sem Terra (MLST) e as Contradições da Luta pela Terra no Brasil" (2000-2002); na Paraíba foram realizadas coletas de dados para tese de doutorado "A Ação Territorial de uma Igreja Radical. Teologia da Libertação, Luta pela Terra e Atuação da Comissão Pastoral da Terra no Estado da Paraíba" (2004-2008); na Bahia coordenei o projeto de pesquisa "Novas configurações no espaço agrário da região sudoeste da Bahia: estudo do Movimento dos Trabalhadores Rurais Sem Terra e do Movimento de Pequenos Agricultores" (2007-2008); e em Sergipe coordenei as seguintes pesquisas: "Movimento Sociais, Políticas Públicas de Reforma Agrária e Desenvolvimento Rural no Estado de Sergipe", ligado ao programa de iniciação científica da Universidade Federal de Sergipe em convênio com o CNPq (2009-2010) e "Da Luta pela Terra à Luta na Terra: situação sócioeconômica dos Projetos de Assentamento em Sergipe" (2010), ligado ao Programa de Auxílio à Integração de Docentes e Técnicos Administrativos e Recém-Doutores às Atividades de Pesquisa (PAIRD) da Universidade Federal de Sergipe - ver bibliografia.
} 
uma dívida frente a um crédito estatal, uma vez que terá no máximo 23 anos para pagar o lote de terra ${ }^{17}$. Isso significa que, antes do pagamento de no mínimo 10 anos regulares, não é possível obter título legal de propriedade, mas sim concessão de uso, portanto, nessas condições, a venda de lotes no mercado imobiliário é impossível do ponto de vista legal ${ }^{18}$.

O domínio territorial, levando em consideração as leis que regem a propriedade privada da terra no Brasil, é inexistente se se considera apenas essa dimensão do domínio da terra pelos assentados. No entanto, a luta pela terra que garantiu às famílias o direito de concessão de uso e a possibilidade de se tornarem pequenos produtores e futuramente proprietários permite a precedência desses sujeitos sobre a área em questão, portanto um domínio relativo sobre a terra.

O município de Canindé de São Francisco (SE) é exemplar no que se refere ao domínio territorial das famílias assentadas. Às margens do Rio São Francisco e próximo à Usina Hidrelétrica de Xingó, Canindé de São Francisco possui em seu perímetro municipal a presença de 25 assentamentos rurais, realidade que evidentemente alterou a dinâmica social, econômica, demográfica e territorial do município. O domínio dessa população assentada das terras conquistadas/concedidas e sua influência no cotidiano municipal é eminente, porém não se faz sem contradições.

2 - Os 25 assentamentos no entorno do município em voga são produtos da luta pela terra iniciada pela Comissão Pastoral da Terra e impulsionada pelo Movimento dos Trabalhadores Rurais Sem Terra no alto sertão sergipano. Inclusive, foram as lutas travadas nessa região que ajudaram a fortalecer esse movimento social no Estado de Sergipe, o que fez caracterizar o alto sertão em um espaço por excelência de disputa política nos últimos 20 anos. Em contento a essa realidade, esse espaço político sofreu uma transformação territorial após a desapropriação de grande parte dos latifúndios e, em consequência, recebeu um acréscimo populacional significativo. Em termos da

\footnotetext{
${ }^{17}$ Vale a ressalva de que, na compreensão equivocada da sociedade civil, entende-se que a terra conquistada pelas famílias sem terra são doadas ou dadas pelo Estado. Não é por menos que a expressão "ganhar a terra" é frequentemente encontrada nas conversas sobre tema. Esse entendimento, vale repetir, equivocado, ajuda em uma formação pejorativa da opinião pública frente aos movimentos sociais no campo.

${ }^{18}$ Não existem dados que dimensionem o que a grande mídia compreende como venda de "lotes de reforma agrária". O próprio governo federal e os movimentos sociais reconhecem essa prática intitulada de "repasse", uma vez que a venda da terra é impossível realizar-se nos trâmites legais. Em um pronunciamento do ex-ministro do Ministério de Desenvolvimento Agrário em 1999, Raul Julgmamm afirmava que apenas $11 \%$ dos lotes de todos os projetos de reforma agrária teriam passado por esse processo.
} 
política institucional, foram aproximadamente três mil novos eleitores que entraram no jogo político local ${ }^{19}$. O fato de as famílias assentadas jamais terem elegido um representante oriundo do movimento social ou das associações de assentamento para a Câmera Legislativa desse município é sintomático da fragilidade da força política e do domínio territorial alcançado na luta pela terra. Pressupunha-se - e essa pressuposição surgiu nas entrevistas de campo - que a política institucional do referido município fosse altamente disputada por elites locais e até estaduais devido ao alto orçamento adquirido com os royalties da Usina Hidrelétrica de Xingó.

Portanto, o jogo político da velha oligarquia nordestina estende-se para áreas onde sujeitos sociais contestadores conquistaram frações de terra, fazendo com que velhas relações, como o clientelismo e o paternalismo político, reproduzam-se nessas novas áreas e com esses novos sujeitos políticos.

3 - A conquista de infraestruturas para os assentamentos rurais faz ampliar relações sociais pautadas no clientelismo e paternalismo. O exemplo de um dos assentamentos desse município (PA Cuiabá) é, a meu ver, reiterado em outras experiências. A morosidade do Estado na implantação da infraestrutura elementar ao assentamento das famílias torna esses sujeitos mais facilmente vítimas do clientelismo político. O PA Cuiabá, mesmo estando a menos de oito quilômetros de um dos maiores rios da federação (rio São Francisco) e de uma importante usina hidroelétrica, demorou oito anos para obter água encanada e seis anos para conseguir o fornecimento regular de energia elétrica, transformando-se numa área para fácil reprodução das relações de favores que caracterizam relações políticas paternalistas entre a administração pública e os sujeitos envolvidos ${ }^{20}$.

\footnotetext{
${ }^{19} \mathrm{O}$ município de Canindé de São Francisco possui um total de 21.806 habitantes. Com a luta pela terra desenvolvida próxima a esse município, os 25 assentamentos conquistados nos últimos 20 anos congregaram 1.912 famílias beneficiárias. Se levarmos em consideração que cada família possui em média quatro integrantes, o número total de pessoas nas áreas de assentamento pode chegar a 7.648. Vale ainda considerar que os assentamentos rurais em todo Brasil aglutinam outros familiares ao local de residência, o que é popularmente chamado de agregados, ampliando ainda mais o número de pessoas residentes. O assentamento Cuiabá no município em questão e um bom exemplo. Segundo lideranças locais, são 199 famílias assentadas, porém a agrovila do assentamento congrega 215 famílias.

${ }^{20}$ Outro evento facilmente reprodutor de relações clientelistas ocorre no momento da liberação dos créditos às famílias assentadas. Muitas empresas de produtos agropecuários e de material de construção dos municípios próximos ao(s) assentamento(s) se organizam para vender suas mercadorias aos assentados beneficiários de um montante em dinheiro que objetiva levar adiante o processo de assentamento. Ocorre uma corrida por clientes no momento da liberação dos créditos, principalmente em municípios com uma grande quantidade de famílias assentadas, como figura em Canindé de São Francisco. Inflação dos preços, disputa de mercado, acordos com comerciantes podem reproduzir relações de favores que fazem perpetuar relações efetivamente desiguais entre os envolvidos.
} 
4 - Deve-se levar em consideração a análise feita por Martins (2003) mesmo que em muitos momentos essa análise apareça de forma pejorativa. Para esse autor, o assentado é visto como um sujeito ambíguo, dilacerado pela contradição entre a situação social de trabalhador e a situação social de proprietário de renda fundiária.

$\mathrm{O}$ assentado na condição de ex-sem terra é agora um pequeno agricultor. Nessa condição - dentro de uma sociedade capitalista que sua luta visa negar -, para se reproduzir enquanto família camponesa, ele deve produzir renda, que no fim acaba sendo a reprodução da renda da terra. Boa parte dessa renda necessária à subsistência provém das relações mercantis que evidentemente ocorrem no mercado, segundo as normas capitalistas de compra e venda, oferta e demanda, oscilação de preços e juros, transporte, atravessadores etc. As contradições essenciais decorrentes dessa realidade não se encontram apenas na comparação entre o discurso de transformação social (e consequentemente de uma nova sociedade) do período de luta e a realidade encontrada a partir da posse da terra, mas também na totalidade das relações que se desenvolvem entre aspirações dos movimentos sociais, aspirações das famílias camponesa, a estrutura do Estado e suas políticas públicas e o mercado capitalista.

A pobreza das infraestruturas básicas oferecidas a uma pequena exploração agropecuária particularizada pela sua história de luta pela terra; a fragilidade diante do mercado; a dependência do Estado; uma certa subserviência às instituições políticas locais e as divergências internas ao movimento social parecem ampliar a noção de ambiguidade de Martins (2003). Porém, penso que o que de fato se produz não é um sujeito ambíguo, mas sim um sujeito único, que a partir da sua resistência gera também subordinação, ou através de relações subordinadas continua resistindo para se reproduzir enquanto camponês assentado.

5 - Trabalhei com a noção de "pequenas revoluções" na minha dissertação de mestrado (Mitidiero, 2002) para pensar os limites e parcialidade das conquistas alcançadas a partir da luta organizada pela terra. As conquistas impulsionadas pelos movimentos sociais organizados, impensáveis anos atrás, significaram revolucionar social e territorialmente famílias e áreas/regiões onde os eventos de contestação e 
reivindicação aconteceram. $\mathrm{O}$ adjetivo pequeno serviu para dimensionar as revoluções ocorridas. $\mathrm{O}$ exemplo mais básico a ser usado é comparar a área dominada por um ou mais latifúndios improdutivos com a área povoada e dividida após a conquista do assentamento. Isto quer dizer: não foi alterada a estrutura fundiária nacional, porém, naquele âmbito espacial, ocorreu uma série de transformações. A ideia ora em voga objetiva desvendar a contradição entre resistência e subordinação. Nos casos pesquisados, a análise das histórias de vida e das condições da estrutura fundiária local indicou que "pequenas revoluções" emergiram da organização popular, o que a gabaritou a produzir uma série de resistências, tanto no âmbito das vidas particulares de uma família camponesa que se reproduz como nas disputas de poderes locais. O desafio é não abstrair desse processo todos os eventos que indicam a subordinação dessas famílias e dessa fração do território conquistado/concedido a uma sociedade que a envolve, reprodutora de relações econômicas, sociais, políticas e culturais capitalistas.

\section{REFERÊNCIAS BIBLIOGRÁFICAS}

ALENTEJANO, Paulo Roberto. Os Movimentos Sociais e a Teoria Geográfica. In: MARFON, G. S.; RUA, J., RIBEIRO, M. (Orgs.). Abordagens teóricometodológicas em Geografia Agrária. Rio de Janeiro: UERJ, 2007.

Pluriatividade: uma noção válida para a análise da realidade agrária brasileira? Rio de Janeiro: CPDA/UFRRJ (mimeo) 1998.

BERGAMASCO, Sonia M. P. Pereira. A realidade dos assentamentos rurais por detrás dos números. Revista de Estudos Avançados. São Paulo, v. 11, 1997.

CARVALHO, HORÁCIO MARTINS - Interação Social e as Possibilidades de Coesão e de identidades Sociais no Cotidiano da Vida Social dos Trabalhadores Rurais nas Áreas Oficiais de Reforma Agrária no Brasil. Curitiba: Nead - Núcleo de Estudos Agrários e Desenvolvimento Rural, 1999.

FERNANDES, BERNARDO MANÇANO. - MST: movimento dos trabalhadores rurais sem terra, formação e territorialização em São Paulo. São Paulo: Hucitec, 1996.

HARVEY, DAVID - Espaços de Esperança. São Paulo: Edições Loyola, 2004.

LEITE, S., HEREdiA, B., MEdEIROS, L., PALMEIRA, M., CINTRÃO, R. Impactos dos Assentamentos: um estudo sobre o meio rural brasileiro. São Paulo, UNESP/Nead, 2004.

MARTIN, JEAN-YVES - Uma Geografia da Nova Radicalidade Popular: algumas reflexões a partir do caso do MST. São Paulo: In. Terra Livre, Associação dos Geógrafos Brasileiros, v. 12, n 19, 2002.

MARTINS, JOSÉ DE S. - O Sujeito Oculto. Ordem e transgressão na reforma agrária.Porto Alegre: Editora Universidade Federal do rio Grande do Sul, 2003. 
MARQUES, MARTA I. MEDEIROS - De Sem Terra a "Posseiro", A Luta pela Terra e a Construção do Território Camponês no Espaço da Reforma Agrária: O Caso dos Assentados nas Fazendas Retiro e Velha - GO. São Paulo: Dissertação de Mestrado, Faculdade de Filosofia, Letras e Ciências Humanas da Universidade de São Paulo, 2000.

MEDEIROS, LEONILDE; LEITE, SERGIO - Assentamentos Rurais. Mudança Social e Dinâmica Regional. Rio de Janeiro: MAUAD, 2004.

MITIDIERO, MARCO ANTONIO Jr. - a Ação Territorial de uma Igreja Radical. Teologia da Libertação, Luta pela Terra e Atuação da Comissão Pastoral da Terra no Estado da Paraíba. Curitiba: CRV Editora, 2010.

O Movimento de Libertação dos Sem Terra (MLST) e as Contradições da Luta pela Terra no Brasil: São Paulo. Dissertação de Mestrado. Departamento de Geografia, Faculdade de Filosofia, Letras e Ciências Humanas da Universidade de São Paulo, 2002.

MIRANDA, MARIA ELENA - Análise de uma situação de conflito entre os assentados e o MST. São Paulo: Dissertação de Mestrado. Departamento de Antropologia, Faculdade de Filosofia, Letras e Ciências Humanas da Universidade de São Paulo, 1998.

MORAIS, J, F, REGIS - Os Bispos e a Política no Brasil. São Paulo: Editora Cortez/Editora Autores Associados, 1982.

MOREIRA, EMÍLIA - Território(s) de Esperança. Projeto de pesquisa: JoãoPessoa, CNPq, 2006.

OLIVEIRA, ARIOVALDO UMBELINO - Modo capitalista de produção e agricultura. São Paulo : Ática, 1986.

A agricultura camponesa no Brasil. São Paulo: Contexto, 1991.

SIMONETTI, MIRIAM C. LOURENÇÃO - A Longa Caminhada: A (Re) Construção do Território Camponês em Promissão. São Paulo: Tese de Doutorado. Departamento de Geografia, Faculdade de Filosofia, Letras e Ciências Humanas da Universidade de São Paulo, 1999. 